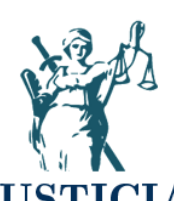

JUSTICIA

ISSN impreso 0124-7441
ISSN digital 2590-4566

\title{
Tres modelos y un mismo objeto de interpretación de los derechos fundamentales: Dworkin, Alexy y Sieckmann
}

\section{Three models and the same object of interpretation of fundamental rights: Dworkin, Alexy and Sieckmann}

\author{
Abraham Zamir Bechara Llanos \\ Corporación Universitaria del Caribe - CECAR, Colombia \\ abraham.becharall@cecar.edu.co \\ Maria Eugenia Vides Argel \\ Corporación Universitaria del Caribe - CECAR, Colombia \\ maria.vides@cecar.edu.co
}

Recibido: 10 de diciembre de 2018 / Aceptado: 7 de febrero de 2019

https://doi.org/10.17081/just.24.36.3765

\section{Resumen}

El presente artículo refleja tres posturas en torno a un mismo objeto de estudio, nos referimos a la interpretación principialista de los derechos fundamentales en la ciencia jurídica y el derecho contemporáneo. En primer lugar, mostramos los desarrollos teóricos de quien es considerado el padre de la principialista jurídica Ronald Dworkin. En ese tópico reflejamos el debate Dworkiniano en clave de las críticas que establece frente al modelo de discrecionalidad juridicial elaborado por Hart en su texto capital el concepto de derecho. En un segundo momento del texto, presentamos la teoria de principios ampliada por Robert Alexy en su Teoría de los derechos fundamentales y desde la visión prima facie como normas optimizables o por optimizar. Finalmente, en el tercer escenario argumentativo evidenciamos la visión de Jan-R Sieckmann de los principios como argumentos normativos de razones, al considerar que los principios deben ser un enlace entre la interpretación constitucional y la argumentación jurídica.

Palabras Clave: teoría del derecho; interpretación constitucional; argumentación jurídica.

\begin{abstract}
This article reflects three positions around the same object of study; we refer to the principialist interpretation on the right. First we show the theoretical developments of who is considered the father of Ronald Dworkin legal principialist. In that reflect the debate Dworkiniano in key states criticisms against the model developed by Hart juridicial discretion in its capital text concept of law. In a second stage of the text, we present the theory of principles augmented by Robert Alexy in his theory of fundamental rights and from raw vision facie tunable standards or optimize. Finally in the third argumentative stage, we show the vision of Jan-R Sieckmann principles as normative arguments of
\end{abstract}

Justicia Vol. 24 No. 36: pp. 196-213. Julio - diciembre, 2019. DOI: 10.17081/just.24.36.3765

(C) Copyright 2019 by Bechara Llanos, A \& Vides Argel, V

$$
\text { OPEN } \odot \text { ACCESS (c) (1) }
$$


reasons, considering that the principles should be a link between constitutional interpretation and legal argument

Keywords: theory of law; constitutional interpretation; legal reasoning.

\section{Como citar:}

Bechara Llanos, A. Z., \& Vides Argel, M. E. (2019). Tres modelos y un mismo objeto de interpretación de los derechos fundamentales: Dworkin, Alexy y Sieckmann. Justicia, 24(36), 196-213. https://doi.org/10.17081/just.24.36.3765

\section{INTRODUCCIÓN.}

La teoría de los derechos fundamentales a partir de la teoría constitucional contemporánea, parte de la construcción teórico-conceptual denominada, "El derecho más allá de la ley", como propuesta a la superación del paradigma positivista por un derecho construido por principios. Como segundo momento el plano de la distinción entre reglas y principios como fórmula de superación entre ley y derechos propone la defensa de ver "El derecho por principios", puntualmente desde el papel que juegan las normas jurídicas de principios en el Estado constitucional. Como primer lugar para el nacimiento de una principialista jurídica cabe resaltar la teoría de Ronald DWORKIN desde sus críticas y debate sobre el modelo de las normas, específicamente en Los derechos en serio en contra posición a lo propuesto por Hart en su concepto de derecho.

El plano de la teoría de DWORKIN muestra más un escenario propio para la teoría del derecho, pero es con la teoría de los principios de Robert ALEXY como un apéndice de su Teoría de los derechos fundamentales, que se torna trascendental el papel de las normas de principio para entender a la dogmática constitucional contemporánea, y los recientes influjos normativos en las normas de derechos fundamentales. Sumado a estas grandes concepciones Jan-R Sieckmann, plantea la idea de que los principios constitucionales y su estructura normativa como derechos fundamentales, no son oponible a una argumentación jurídica especial, como lo es desde la propuesta del profesor alemán, en considerar que los principios vistos como argumentos normativos de razones construyen una argumentación constitucional fundamental.

Nuestro modelo metodológico contrastará, la teorización en torno a la interpretación constitucional de conformidad con el derecho construido por principios. Como problema de investigación, identificamos los alcances de las distinciones teóricas de la teoría principialista como punto común entre tres modelos distintos a saber, los modelos principialistas de: DWORKIN, ALEXY y SIECKMANN. Tres modelos referenciados, no solo en el contexto doctrinal y dentro de la academia del derecho en Colombia, sino; sopesados jurisprudencialmente por nuestra Corte Constitucional, tanto en sede de constitucionalidad como de amparo. 


\section{LA TEORÍA PRINCIPIALISTA DE RONALD DWORKIN}

Ronald DWORKIN, como exponente de un nuevo iusnaturalismo o neoiusnaturalismo, entra a debatir directamente desde su propuesta teórica, con los exponentes más sólidos del positivismo jurídico en su versión anglosajona. Nos referimos a Jhon AUSTIN y a Herbert Lionel HART. La teoría principialista de Dworkin se enmarca por una redefinición o una nueva concepción del concepto de derecho, orientado al modelo de las normas, y de los mandatos que pueden constituirse en verdaderas obligaciones jurídicas a la hora de aplicar y de resolver los conflictos normativos desde del derecho como integridad ${ }^{1}$.

DWORKIN, destaca que el uso de la fuerza o de la coerción ${ }^{2}$ como imperativo categórico del derecho propuesto por AUSTIN, se queda corto para demostrar que un derecho y un sistema normativo no pueden responder a las órdenes de un soberano, y que este a su vez genera un mandato de cumplimiento de los poderes públicos, por el simple hecho de existir un conjunto de reglas que te obliguen a hacerlo.

En este sentido, la gran critica que plantea DWORKIN sobre el positivismo jurídico y por ende del modelo de derecho de HART, es precisamente el uso indiscriminado que se le da a los operadores jurídicos (jueces) cuanto tengan que resolver "casos jurídicos", donde la aplicación de la norma valida al caso ${ }^{3}$ concreto no encuentre su relación con la generación correlativa de la obligación jurídica, encuadrando en el supuesto normativo, para resolver "el conflicto de reglas", sea por la vaguedad o ambigüedad del lenguaje o por que no exista norma jurídica aplicable, el juez podrá hacer uso de su discrecionalidad ${ }^{4}$.

${ }^{1}$ La integridad del derecho en Dworkin, abre el escenario jurídico desde el reconocimiento en la existencia de planos no estrictamente normativos, según el modelo Dworkiniano, el derecho también encuentra un gran espacio de acción en el contexto, entendiendo como tal, no solo lo jurídico sino lo social. Aguilera destaca la importancia de tal teoría basada en su concepto de integridad: "Uno de los grandes méritos de la filosofía de Dworkin consiste en el enfoque del Derecho desde la perspectiva de la integridad, sin duda una perspectiva que arremete contra la concepción simplista y reduccionista que posee actualmente el positivismo."(Aguilera, 2009, p. 2). En: Aguilera, R. (2009). La función de la filosofía política y jurídica en Ronald Dworkin. En: Revista Multidisciplinar del Centro de estudios sobre derecho, globalización y seguridad. Universidad Veracruzana. Núm. 20. Año 10. pp. 1-16.

${ }^{2}$ La reducción del derecho simplemente a normas estrictamente encuadradas en el plano jurídico, no podrían responder a las demandas de aplicación del derecho en los casos concretos frente a situaciones difíciles o complejas pues si bien plantea, que la propuesta de Austin es óptima para el explicar la sujeción de los poderes públicos a una especie de poder superior, se queda corta para responder a las demandas sociales y morales de un derecho, visto desde escenarios políticos y democráticos, por la proliferación de escenarios pluralistas en la conformación de las reglas del derecho, y de cómo la misma cultura jurídica se forma su visión de obligación y mandato jurídico apoyándose ya no solamente en el plano estrictamente legal.

${ }^{3}$ Sobre esta postura se sienta el debate propuesto por Dworkin sobre el modelo de las normas aplicable por un derecho basado en un positivismo jurídico, pues en los casos donde la norma valida aplicable en concreto no pueda responder, sea porque el mismo lenguaje jurídico presenta una indeterminación, que imposibilite reconocer la regla jurídica a aplicar, o porque no exista dentro del mismo ordenamiento o sistema jurídico una disposición que responda de manera satisfactoria las necesidades del caso.

4 "El conjunto de estas normas jurídicas validas agota el concepto de <<derecho >, de modo que si alguna de tales normas no cubre claramente el caso de alguien (porque no hay ninguna que parezca apropiada, o porque las que parecen apropiadas son vagas o por alguna otra razón), entonces el caso no se puede decidir <<aplicando la ley>>. Ha de ser decidido por algún funcionario, por ejemplo, un juez <<ejerza su discreción〉>, lo que significa ir más allá de la ley en busca de algún 
El sistema de normas se desarrollaría en el sentido, ya no estrictamente reglado del positivismo jurídico, en la búsqueda de desmitificar un concepto del derecho basado únicamente en la figura del legislador racional como autoridad suprema de todo sistema normativo. Debido a que los estándares utilizados para darle respuesta al derecho en los casos difíciles rompen con la concepción reglada al superar la idea central del positivismo jurídico de una única de derecho legislativa e híper legal, apoyándose DWORKIN por la apertura a los principios y las directrices políticas, como otro tipos de normas inmersas en los ordenamientos jurídicos y que posibilitan respuestas correctas, el problema de los casos difíciles, cuya complejidad en sistemas normativos cerrados al modelo puro de reglas no podrían ofrecer respuestas acertadas o $\operatorname{correctas}^{5}$ para el derecho.

El gran logro de la teoría desarrollada por DWORKIN, está en introducir a través de los principios elementos morales que respondan a postulados de justicia en el derecho, pues el reconocimiento de los principios como nuevos estándares en la interpretación y actividad del modelo judicial, permiten orientar a la ciencia jurídica más a un cometido aspiracional consecuente con las necesidades de la sociedad en tiempos de modernidad. Este avance de DWORKIN va a ser desarrollado, desde la tesis de la conexidad necesaria entre el derecho y la moral, como elemento de pretensión de corrección del sistema jurídico, según ALEXY. Para explicar que el derecho pretende corregir la moral y eticidad que no llega a convertir se en una justicia material, siendo corregida por la aplicación justificada del derecho.

Sobre la propuesta estrictamente normativa de la teoría principialista de DWORKIN, busca desmitificar la función discrecional del juez, como único medio posible para resolver los problemas del derecho frente a los casos difíciles o complejos, pues el derecho más allá de la ley que propone DWORKIN, no es el derecho del positivismo jurídico basada en la posición discrecional del operador jurídico, sino en el derecho por principios, o en un modelo de normas caracterizado por principios ${ }^{6}$.

En este entendido, la diferencia entre el positivismo jurídico basado en una fuente de producción del conjunto normativo en las reglas jurídicas ${ }^{7}$, se apartará de la propuesta

otro tipo de estándar que lo guie en la preparación de una norma nueva o en la aplicación de una existente". (Dworkin, 1984, pp. 65-66).

${ }^{5}$ Sobre la tesis de la única respuesta correcta desde la perspectiva de Dworkin, Alexy encuentra un punto de quiebre teórico desde las vistas iuspositivistas, especialmente las de Hart y Kelsen: "La tesis de Dworkin de que existe una única respuesta correcta para cada caso se incluye en una teoría de los sistemas jurídicos que se distingue fundamentalmente de teorías positivistas como las de Hart y Kelsen. Según la perspectiva positivista, el sistema jurídico es, al menos en lo esencial, un sistema de reglas que se pueden identificar como reglas jurídicas sobre la base de su validez y/o eficacia". (Alexy, 1993, p.7). En: Alexy, R. (1993). Derecho y razón práctica. Distribuciones Fontamara. México, D.F.

6 "Llamo <<principio>> a un estándar que ha de ser observado, no porque favorezca o asegure una situación económica, política o social que se considera deseable, sino porque es una exigencia de la justicia, la equidad o alguna otra dimensión de la moralidad. (Dworkin, 1984, p.72)".

${ }^{7}$ Si bien el modelo de principios encuentra diferencias con el modelo de normas vistas como reglas, la segunda gran tesis defendida por Dworkin sobre su concepto de derecho, va a estar determinada por la apreciación que hace sobre las controversias que se generan cuando dos principios se van aplicar simultáneamente, si bien, Dworkin a diferencia de Alexy, no habla concretamente de la ponderación judicial o del juicio de ponderación. Establece una segunda distinción sobre el modelo puro de reglas sustentado desde la versión del positivismo de Hart. Y es precisamente la dimensión del peso, de los principios que los identifica de las reglas, pues los principios tendrán un peso relativo, y que el aplicador o intérprete deberá establecer para solucionar los casos difíciles. 
reivindicadora de una moral en el derecho, pero apoyada en la aceptación social de los principios que emergen de la colectividad. Tal distinción se apoya de la separación que hace DWORKIN de las normas (reglas) jurídicas y de los principios jurídicos. Para determinar que la forma de aplicar las reglas de diferencia de la forma de aplicar los principios pues siempre la aplicación de las reglas generará disyuntivas para el operador jurídico, cuando no encuentre la norma válida aplicable al caso concreto. De la forma todo o nada se aplican al modelo reglado de las normas, mientras que el modelo de principios ${ }^{8}$ se presenta una interpretación como superación de la discrecionalidad de la que tienen los jueces en un modelo puro orientado por el positivismo jurídico.

"El ataque" a la discrecionalidad judicial defendida por el positivismo jurídico, busca determinar que la presentación en los términos de HART según DWORKIN de dicho modelo, presenta rasgos de falta de limitación frente a su uso con libertad, por parte del juez en el pleno de su actividad. Concretamente el autor americano, plantea que existen dos elementos comunes para entender la discrecionalidad judicial, uno es su posición débil y otro es su posición fuerte. La posición débil va a estar orientada a una discrecionalidad donde el operador tiene un rango de acción múltiple para tomar la decisión que considere correcta, pero tiene o puede enfrentar dilemas por cuál de ellas escoger.

Y la posición fuerte desarrolla el postulado que considera que una decisión puede enfrentar una respuesta no conocida por el derecho vigente, por la sencilla razón de que no existe en el caso concreto un precedente legislativo a aplicar. Sobre este mismo punto en especial, HABERMAS $^{9}$ (2008) adopta una postura en defensa a la teoría de DWORKIN, sobre el entendido de los desarrollos del derecho y sus órganos de aplicación frente a la racionalidad de los procedimientos legislativos de producción del derecho vigente.

La crítica de DWORKIN se estructura sobre la base en determinar que el uso de la discrecionalidad ${ }^{10}$ judicial no puede ser un uso ilimitado de su forma y alcance, porque lo importante y fundamental no es, que no existe norma validad que ayude la construcción de una respuesta correcta o acertada en derecho, ni además que el aplicador u operador jurídico no sepa por cuál de las múltiples opciones se pueda inclinar para formar su sentido valorativo reflejada en la decisión judicial; sino lo realmente

\footnotetext{
8 "La diferencia entre principios jurídicos y normas jurídicas es una distinción lógica. Ambos conjuntos de estándares apuntan a decisiones particulares referentes a la obligación jurídica en determinadas circunstancias, pero difieren en el carácter de la orientación que dan. Las normas son aplicables a la manera de disyuntivas. Si los hechos que estipula una norma están dados, entonces o bien la norma es válida, en cuyo caso la respuesta que da debe ser acertada, o bien no lo es, y entonces no aporta nada a la decisión". (Dworkin, 1984, p. 74-75).

${ }^{9}$ Habermas encuentra, un punto de convergencia con la teoría de Dworkin, puntualmente, a lo que tiene que ver con lo planteado en su texto los derechos en serio, entrando a determinar que la aplicación del derecho vigente se ve sesgada, por la superioridad procedimental de la rama legislativa del poder público: “Como la práctica de las decisiones judiciales está ligada al derecho y a la ley, la racionalidad de la administración de justicia depende de la legitimidad del derecho vigente. Esta depende a su vez de la racionalidad de un proceso legislativo, que, en la situación de división de poderes que el Estado de derecho establece, no está a disposición de los órganos de aplicación del derecho". (p. 311).En: Habermas, J. (2008). Facticidad y validez. Quinta edición, Trad. de Manuel Jiménez Redondo. Editorial Trotta. Madrid, España.

10 “Como sucede con casi todos los términos, el significado exacto de <<discreción >> se ve afectado por las características del contexto. (...) usamos este sentido no como comentario de la vaguedad o dificultad de las normas, ni para referirnos a quien tiene la última palabra en su aplicación, sino para aludir a su alcance y a las decisiones que pretenden controlar". (Dworkin, 1984, pp. 84-85).
} 
importante está en los alcances de la decisión, y de cómo ellos no solo trascienden a las partes inmersas dentro del conflicto de interés o litigio concreto, y el impacto que genera frente a la sociedad.

En este sentido, la discrecionalidad judicial defendida por los positivistas va a estar fuertemente arraigada, a la idea que concibe el derecho, única y exclusivamente como un sistema de normas, entendiendo por nomas, claro está, un modelo puro de reglas. DWORKIN, plantea que la posición de una discrecionalidad judicial basada en un derecho aceptado por los positivistas, bajo el modelo puro de reglas, desconoce normas del mismo conjunto normativo, como van a hacer los principios jurídicos. Reconociendo que la misma actividad judicial, desarrollada por los jueces unipersonales, como la desplegada por los tribunales colegiados, construyen sus decisiones a partir de una interpretación del derecho, cuando en los casos concretos la norma validad aplicable, no responde los estándares normativos básicos sobre los cuales el operador jurídico pueda fundamentar su decisión.

A este problema, DWORKIN lo va a identificar como la defensa de la discrecionalidad judicial ${ }^{11}$ por parte del positivismo jurídico desde su posición débil, pues no es solamente aplicar la norma valida cuando exista precedente legislativo en específico, sino desde la variabilidad de las posiciones en las cuales el juez ${ }^{12}$ pueda fundamentar su decisión, se apoye en la más correcta, para impedir que con su actividad se produzca un error jurídico, que determine el desconocimiento de un derecho para la parte o partes interesadas en el conflicto normativo.

DWORKIN, en este punto de su teoría, es totalmente fulminante en su conclusión, en contra de los postulados del positivismo, al establecer, que simplemente el uso de la discrecionalidad judicial, puede ser planteada como el empleo de juicio o de juicios por parte del operador jurídico en su formación de la decisión judicial, es decir la discrecionalidad debe ser un juicio que emplea el juez cuando para determinar la norma valida aplicable al concreto no existe solución aparente respaldada por otra norma del mismo tipo o estructura dentro del ordenamiento jurídico, con lo que quiere diferenciar es, que si existe otra norma con una estructura o tipo totalmente distinta a la reglas

\footnotetext{
${ }^{11}$ Frente a esta propuesta, el entendido de una discrecionalidad judicial que no reconoce como elemento integrante de su concepción a los principios, desbordaría los límites del uso racional, debido a que el juez, construiría para él, conforme a su "sentido del derecho" mas no al alcance material del mismo contenido de justicia; la decisión que más encuentre conveniente para tomar su determinación en el caso particular. El reconocimiento de una discrecionalidad se volvería trivial en palabras de Dworkin, ya que se estaría validando dentro del mismo modelo positivista, que los principios nunca podrían considerarse como normas dentro del mismo sistema jurídico, debido a su formación vista así, desde el positivismo jurídico, como extrasitemica. Oponiéndose radicalmente a la visión defendida por el profesor norteamericano, de los principios como normas construidas y formadas al interior del mismo sistema jurídico-normativo.

12 "Un positivista podría afirmar que los principios no pueden considerarse como derecho porque su autoridad, y mucho más su peso, son discutibles por naturaleza. Es verdad que generalmente no podemos demostrar la autoridad o el peso de un principio determinado como podemos a veces demostrar la validez de una norma, localizándola en un acta del Congreso o en la opinión de un tribunal autorizado. En cambio, podemos defender un principio $-\mathrm{y}$ su peso- apelando a una amalgama de prácticas y de otros principios en la cual cuenten las implicaciones de la historia legislativa y judicial, junto con referencias a prácticas y sobreentendidos comunitarios. No hay un criterio valido que sirva como prueba de la solidez de un caso así; es una cuestión de juicio, y entre hombres razonables puede haber desacuerdos. Pero una vez más, esto no distingue al juez de otros funcionarios que no tienen discreción". (Dworkin, 1984, pp. 89-90).
} 
(principios) el juez empleando su juicio y su criterio jurídico puede tomar la determinación en específico.

Por otro lado, DWORKIN, se apartará de la aceptación de una regla maestra que vincule todo el ordenamiento jurídico, como lo es la regla de reconocimiento de HART. Ya que no puede explicar la existencia de los principios en la coexistencia con las reglas como el conjunto de normas del ordenamiento, indicando que la idea de una regla maestra que vincule las demás reglas (normas) de la noción general que construye el concepto de derecho se aparta especialmente de la validación de los principios, ya que según DWORKIN los principios no pueden medirse por su validez como las reglas, ya que estas (los principios) en su mayoría de los casos, no están sometidas a la autoridad del soberano del cual ellas emanan, de la actividad de los tribunales o del mismo desarrollo de los precedentes legislativos:

(...) Hay que decir que los principios no convergen, sino que coexisten. De modo que aun, cuando se apoyen en los actos oficiales de instituciones jurídicas, los principios no tienen con tales actos una conexión lo bastante simple y directa como para que quede enmarcada en función de los criterios especificados por alguna regla maestra final de reconocimiento. (...) sin embargo, debemos considerar una posibilidad más. Si ninguna regla de reconocimiento puede proporcionar un criterio para la identificación de principios, ¿Por qué no decir que los principios son decisivos y que ellos forman la regla de reconocimiento de nuestro derecho? (Dworkin, 1984, pp. 96-99).

Es claro que DWORKIN, abre al derecho al mundo de los principios, por eso es considerado como el padre de la principialista jurídica. Destacando que las controversias entre principios siempre se van a generar, lo importante es destacar que ya no existe una discrecionalidad absoluta en el modelo de construcción de la decisión judicial, y que a la hora de establecer respuestas correctas para el derecho, la interpretación de principios arrojaría rasgos comunes, que posibilitarían encontrar escenarios de justicia, donde una aplicación del modelo de las normas, no arrojaría la llegada de la norma jurídica valida aplicable al caso concreto. "Los principios tienen una dimensión que falta en las normas: la dimensión del peso o importancia. Cuando los principios se interfieran quien debe resolver el conflicto tiene que tener en cuenta el peso relativo de cada uno". (Dworkin, 1984, p. 77).

Esta "dimensión del peso" de los principios plantea un escenario totalmente nuevo de conformidad lo que se había construido hasta ese momento (década de los 70 del siglo XX), nos referimos desde el plano de la teoría jurídica y la filosofía del derecho. Ya que la discusión se centraba únicamente en los problemas de indeterminación normativa, generada de - la teoría general de las normas - su uso discursivo, y el papel del lenguaje jurídico frente a los casos difíciles y $\operatorname{complejos}^{13}$. La reconceptualización del

\footnotetext{
${ }^{13} \mathrm{Si}$ bien en este punto de su teoría Dworkin, no habla de una ponderación judicial de bienes o intereses jurídicos contrapuestos, formula la intensión de una interpretación apoyada a las consideraciones que fundamenten una decisión judicial sustentadas en la esfera de lo razonable. Pues el enfoque, busca integrar el derecho a través de principios que consoliden una mirada de conjunto del mismo sistema normativo, para solucionar los casos difíciles, la trascendencia de las mismas normas superaría la colisión de principios en un plano material como lo es llevado a través del método o el modelo ponderativo de adjudicación del derecho, a mi parecer la propuesta Dworkiana apela a un modelo donde los principios sean parámetros interpretativos como cualquier
} 
derecho en términos de DWORKIN por una propuesta principialista, puso en la mesa el debate por las fuentes de producción del derecho, pero, al introducir esta dimensión de la importancia de los principios contrapuestos entre sí, advirtió que lo fundamental y transcendental de esta teoría no era determinar si un principio superaba al otro por el mayor grado en su peso ${ }^{14}$ relativo.

En este mismo entendido, se configura así un tercer aporte vital para la ciencia jurídica contemporánea, sobre el papel de los principios en el derecho. Desde los aportes que establece DWORKIN. Según el cual, el papel de los principios cobra una mayor connotación e importancia para su uso en los casos difíciles, así mismo el juez, operador jurídico o tribunal judicial que determine su decisión motivada por principios, construirá la norma aplicable al caso concreto pero yendo más allá, sería la norma que completara el sistema jurídico al apoyarse en ella una decisión futura, siempre y cuando sea adoptada por una autoridad judicial investida con la potestad para ello, es decir, la tercera gran conquista que apoya la teoría principialista de DWORKIN para el mundo jurídico de nuestro días, es que la construcción de la sub-regla o precedente es eminentemente una decisión construida por principios ${ }^{15}$.

Con el fin de establecer una teoría del derecho que tenga como sustento principal un modelo argumentativo basado especialmente en la interpretación ${ }^{16}$ de principios, DWORKIN, supera la postura representada en el positivismo jurídico de HART basado en un estricto normativismo, al pretender explicar el fenómeno jurídico solo a través de las normas (reglas) que componen los precedentes legislativos. Es así, como DWORKIN mira al derecho desde su carácter principal apoyado en la justificación social ${ }^{17}$.

otra norma del ordenamiento jurídico, apoyándose del modelo de la escogencia de la regla valida aplicable al caso particular y concreto.

14 "Una norma jurídica puede ser más importante que otra porque tiene un papel más relevante en la regulación del comportamiento. Pero no podemos decir que una norma sea más importante que otra dentro del sistema, de modo que cuando dos de ellas entran en conflicto, una de las dos sustituye a la otra en virtud de su mayor peso. Se da un conflicto entre dos normas, una de ellas no puede ser válida. La decisión respecto de cuál es válida y cuál debe ser abandonada o reformada, debe tomarse apelando a consideraciones que trasciendan las normas mismas". (Dworkin, 1984, p. 78).

15“Los principios desempeñan un papel esencial en los argumentos que fundamentan juicios referentes a determinados derechos y obligaciones jurídicas. Una vez decidido el caso, podemos decir que el fallo crea una norma determinada. Pero la norma no existe antes de que el caso haya sido decidido; el tribunal cita principios que justifican la adopción de una norma nueva". (Dworkin, 1984, p. 80).

${ }^{16}$ Bajo esta concepción, los principios resultan vinculantes para los jueces y para los operadores jurídicos, sea porque no existe norma válida aplicable al caso concreto, o porque el juez quiera ir más allá del conflicto de normas o de una colisión de principios superando del plano eminentemente normativo de la contradicción por una dimensión "integradora" del sistema jurídico. Llevando respuestas correctas al derecho, incluso si el tribunal o fallador no tiene los elementos del precedente legislativo para tomar la decisión. Con esta propuesta, se quiere superar totalmente la discrecionalidad del aplicador del derecho, y la superación de la subsunción silogística de un sistema jurídico influenciado eminentemente por el positivismo jurídico, llevando al plano de la interpretación por principios para la construcción de las razones a favor o en contra de determinado derecho particular, es este caso retomando la estructura de las normas de principio como disposiciones claras que expresan en sus contenidos materiales derechos fundamentales.

${ }^{17}$ Con apoyo en otras lecturas, que reflejan la teoría de Dworkin, podemos evidenciar, el papel de lo social en la construcción de su concepto de derecho: "Dworkin piensa que, el derecho es un fenómeno social, que como tal es parte de la vida de los seres humanos y, que por lo mismo, debe ser concebido como una praxis que involucra relaciones sociales reales, más concretamente, una praxis de las partes del proceso. Esta praxis jurídica - "legal practice"-hace necesaria una determinada concepción del derecho que resulta de lo que dichas partes han comprendido 
Finalmente, la propuesta de DWORKIN quiere permear directamente en la actividad judicial ${ }^{18}$, cuando plantea la importancia del juez frente a una sociedad que lo rodea, yendo más allá de la figura del juez vista simplemente como mero reproductor de la ley. Al identificar una tridimensión de lo que puede construir una respuesta a lo que es o debe ser el derecho. Esboza que el derecho presenta tres problemas puntuales. (i). el primero de ellos acerca de los hechos que constituyen el supuesto factico sobre el cual la norma válida aplicable al caso concreto debe actuar. (ii). El segundo problema se estructura con base en la ley a la cual se debe aplicar el supuesto jurídico y finalmente en, (iii). Tercer lugar un problema de justicia del derecho frente a la moralidad y la fidelidad política con la que el juez debe decidir el caso.

Bajo este entendido, la dificultad mayor del derecho, ya no va estar en cual va a hacer la ley que debamos aplicar, sino la pretensión de un acuerdo moral y político en la norma que construye el juez para fundamentar su decisión, y como ese argumento goza de fines morales de reconocimiento universal, para proyectar un impacto benéfico en la sociedad, y es en última medida cuando el derecho genera un escenario de acuerdo entre estos tres elementos que el fin de la integridad del derecho puede ser alcanzado, es decir, la moralidad por si sola o los efectos políticos indeterminados no constituyen una cuestión para el mundo jurídico, lo relevante está en cuento del derecho se reclama cierto contenido de moralidad ${ }^{19}$ y de justicia.

\section{LA TEORÍA DE LOS PRINCIPIOS DE ROBERT ALEXY}

Los principios vistos como derechos fundamentales en su carácter normativo, van a determinar el alcance material de los límites racionales de los derechos constitucionales fundamentales. "Hay dos diversas teorías (Konstruktion) básicas de los derechos fundamentales: una estrecha y rigurosa (eng und strikt), y otra amplia y comprehensiva (weit und umfassend); la primera es denominada "teoría de las reglas", la segunda "teoría de los principios"." (Alexy, 2009, p. 3).

La teoría de los principios desarrollada con especial rigor y claridad conceptual por el profesor y filósofo del derecho alemán Robert ALEXY, va a permitir identificar puntos en común de una dogmática de los derechos fundamentales. Principalmente la teoría de los

mediante la interpretación de lo que está permitido o prohibido". (Rojas Amandi, 2007, p.71). En: Rojas Amandi, V. (2007). Ronald Dworkin y los principios generales del derecho. Editorial Porrúa. DF. México.

${ }^{18}$ Todos estos problemas, se ven presentados desde los acuerdos o desacuerdos que se tienen de lo que debe ser el derecho, por eso, la reformulación de Dworkin sobre el concepto del derecho, va a estar apoyada además de una interpretación abiertamente a principios, entendiendo su fuerte carga valorativa moral, a una integridad del derecho como sistema jurídico que debe ser validado no solo por los aspectos formales que desarrollan en el derecho escrito, dado, reglado o positivo, sino en las formas de validación moral y social de las normas que se tienen en cuenta para que el juez tome su decisión.

19 "La tercera cuestión, de moralidad y fidelidad, es diferente pero también conocida. La gente suele estar en desacuerdo sobre lo correcto y lo incorrecto desde el punto de vista moral, y el desacuerdo moral no presenta ningún problema especial cuando surge en una corte. ¿Pero qué sucede con la cuestión de derecho? abogados y jueces parecen estar con frecuencia en desacuerdo sobre el derecho que gobierna un caso; parecen no coincidir ni siquiera en las pruebas correctas que deben utilizar". (Dworkin, 2012, pp. 16-17).

Justicia Vol. 24 No. 36: pp. 196-213. julio - diciembre, 2019. DOI: 10.17081/just.24.36.3765 
principios $^{20}$ va a determinar soluciones a problemas tales, como la división de competencias entre el tribunal constitucional y el parlamento. Y constituye un punto de partida para responder a la pregunta acerca de la posibilidad y los límites de la racionalidad en el ámbito de los derechos fundamentales. (Alexy, 2007, p. 63). Especialmente se construyó la teoría de los principios apoyándose en la distinción ya recurrente entre reglas y principios, para demostrar que cuando hablamos de reglas, en su sentido normativo, estamos hablando de una estructura de norma legal que no comprende en su carácter epistemológico la estructura de norma de derecho fundamental, en cambio se demuestra que cuando hablamos de principios, estamos en presencia de normas de derechos fundamentales, ya que su estructura es comprendida por una lógica Principialista y de los principales postulados que ella presenta. $Y$ es precisamente la idea de que los principios responden a colisiones y no a conflictos como responden las reglas, los principios se resuelven mediante ponderación en cuanto a sus colisiones, y las reglas mediante subsunción.

En tal sentido, la distinción entre reglas y principios construyó su propia doctrina al tenor de la concepción valorativa de estos dos tipos de normas, pues sé que tanto las reglas como los principios eran normas de igual jerarquía y que respondían a condiciones deónticas similares. Sobre los criterios que se estructuran para determinar cuando estamos en presencia de reglas y cuando estamos en presencia de principios, está el criterio de generalidad, que pregona que las reglas tienen un nivel de generalidad más bajo, que el nivel de generalidad de los principios.

Esto se explica mediante el siguiente ejemplo: cuando la constitución establece que existe un derecho de igualdad, y que todos somos iguales ante la ley. Nos está diciendo con un criterio de generalidad elevado, que aquí un principio constitucional esta direccionando un deber ser colectivo. En cambio, cuando el código sustantivo del trabajo, indica que deberán existir igualdades salariales y de trabajo so pretexto de contradecir el mandato constitucional superior, es un tipo de norma cuya característica es de regla, establece un criterio de generalidad más bajo. El nivel de generalidad de los tipos de normas reglas y principios, se va a constatar en la relación abstracta o concreta que tenga la norma, si tiene pretensiones de generalidad o si esta por el contrario pretende regular en concreto una situación particular.

Finalmente, la distinción entre reglas y principios determinó su punto de partida, no solo en la relación de las reglas y los principios como dos tipos de normas jurídicas, sino además, desde el punto de vista de las medidas que cobijan a unas y otras normas en su aspecto estructural como mandatos de optimización ${ }^{21}$, y se cierra la distinción con la

\footnotetext{
${ }^{20}$ Bechara, A. Estado constitucional de derecho, principios y derechos fundamentales en Robert Alexy. En: Revista Saber Ciencia y Libertad. V. 6, №. 2. pp. 63-76. “Es trascendental en la visión de principios el cambio de paradigma subsuntivo que el operador jurídico venía aplicando en el derecho, ya que la teoría del derecho moderna establece herramientas en el uso de la argumentación jurídica y en el caso especial de los principios, la ponderación. La decisión que se adopta cuando se tiene al frente la aplicabilidad o no de los principios exige un examen en oposición a la fundamentación de la forma "todo o nada" en la justificación de los derechos como reglas". (p.65).

${ }^{21}$ Bajo esta perspectiva los principios constitucionales vistos como mandatos de optimización, van a reflejar el universo de posibilidades fácticas y jurídicas reales de concreción. Ya que si los principios no se aplican en los casos concretos de la forma todo o nada, pueden presentarse diversos grados en la aplicación de los principios. Pero esta posición se va a condicionar a las colisiones con los principios opuestos. Cuando un principio opuesto es precedido por un principio contrario se puede dar el caso que los dos sean vistos como las posibles soluciones a entrar a determinar, al respecto los principios toman también de su propia concreción un peso determinado llevando a cabo la
} 
concepción de entender a las dos tipos de normas ${ }^{22}$ reglas y principios como normas axiológicamente distintas.

Otros aspectos importantes del estudio de la teoría de los principios, son precisamente las colisiones, expresadas como colisiones de principios, que se alude a dicha terminología para determinar no solo, la composición de los principios en su estructura, y las diferencias entre reglas y principios, sino el tema de las colisiones de principios y su método de solución, en la utilización de los principios constitucionales en casos concretos como verdaderos derechos fundamentales.

En primer lugar las colisiones de principios deben ser entendidas como colisiones de normas adscritas a derechos fundamentales. Bajo este entendido las colisiones de principios han de ser resueltas de forma totalmente distinta que los conflictos de normas del tipo de reglas, ya que en las colisiones de principios los dos se encuentran opuestos entre sí, uno permite la acción y el otro la prohíbe, son normas de principios que anteceden a una dimensión de validez, pero si su solución va a estar, en la precedencia de un principio sobre el otro, es decir, en el caso concreto un principio de aplica positivamente y el otro principio se aplica en su forma negativa. Esto indica que el principio que se aplicó, toma un mayor peso concreto que su principio opuesto, y el segundo al no aplicarse no sale del ordenamiento, no se invalida sigue siendo válido, pero en el caso particular este no fue tenido en cuenta por su menor fuerza de concreción.

En segundo lugar, se estructura la dimensión del peso, sobre la base de la "ley de colisión", en la dimensión del peso, esta propende, que la solución de la colisión de principios, sea resuelta sobre los principios contrapuestos, y se utilizaría un rango en abstracto para determinar si los principios en el caso concreto, responden a un peso relativamente mayor que a los intereses contrapuestos. "Se establece entre los principios una relación de precedencia condicionada. La determinación de la relación de precedencia condicionada, consiste en que, tomando en cuenta el caso, se indican las condiciones en las cuales un principio precede a otro". (Alexy, 2007, p. 73). Un principio precederá al otro, si ese abiertamente contrapuesto, a los intereses en la preservación del derecho fundamental, se antepone a la colisión de principios constitucionales.

En torno al concepto de principio, se presentan tres objeciones o críticas que van en contra del propio modelo de principio que desarrolla la teoría de los principios en el marco de la teoría de los derechos fundamentales. Estas tres críticas se fundamentan, la primera en la idea de validez de los principios, si cuando un principio entra en colisión con otro principio, al no aplicarse el de menor peso en el caso concreto se estaría declarándolo con falta de validez dentro del sistema jurídico que lo acoge. La segunda

llamada "formula del peso", que es la manera que se le puede aplicar un peso determinado a cada principio cuando por medio de la ponderación, es decir por aplicación del principio de proporcionalidad en sentido estricto se va a aplicar un principio y no otro, atendiendo a dos posibilidades reales de concreción.

${ }^{22}$ Alexy (2007) se refiere a tal distinción en el sentido del ámbito y de las posibilidades fácticas y jurídicas posibles: "El punto decisivo para la distinción entre reglas y principios es que los principios son normas que ordenan que algo sea realizado en la mayor medida posible, dentro de las posibilidades jurídicas y reales existentes. Por lo tanto, los principios son mandatos de optimización, que se caracterizan por que pueden cumplirse en diferente grado y que la medida debida de su cumplimiento no solo depende de las posibilidades reales sino también de las jurídicas". (pp.67-68).

Justicia Vol. 24 No. 36: pp. 196-213. julio - diciembre, 2019. DOI: 10.17081/just.24.36.3765 
crítica se estructura en la idea de los principios como normas jurídicas de carácter absoluto, lo que imposibilitaría precisamente un uso de ponderación por medio del modelo propio de esta forma de adjudicación del derecho, ya que, si un principio es absoluto y este colisiona con otro principio que, por ser normas de igual jerarquía también el resultado se estimaría en la indeterminación, que en casos concretos no se les pudiera dar peso alguno. Y la tercera objeción o crítica se refiere a la naturaleza de los principios y su concepto amplio, lo que desencadenaría una sobrevaloración de los intereses contrapuestos en colisión, ya que no se podrán delimitar dichos intereses en los casos concretos, dado que el propio concepto de principio es tan amplio, que abarcaría un sinfín de intereses a desarrollarse en las colisiones.

Miremos más detalladamente cada uno de estos tres aspectos. La idea que defiende la validez de los principios y su estudio en una forma concreta apartada de una concepción sistemática, es cabalmente defendido por ALEXY, para demostrar que los principios no son inválidos en la concepción de conjunto, cuando entran en colisiones con otros principios, ya que, por esta razón, al ser declarados con falta de validez, saldrían del ordenamiento jurídico. Lo que ocurre frente a esta objeción, es que los conflictos de reglas y las colisiones de principios responden a un criterio más amplio o con un sentido general que cobija a ambos "choques de normas jurídicas", y es precisamente el concepto de contradicción de norma, lo que se ocasiona en este punto, es que el primer grupo de contradicciones de normas, son los conflictos de reglas. Y estás están en la dimensión de si pertenecen o no al ordenamiento jurídico como tal, es decir a la validez de cada una de ellas.

Este problema lo resuelve el mismo ordenamiento, cuando por medio de su constitución acepta o no que una norma carezca de sentido legal. Mientras que las contradicciones de normas que se refieren a las colisiones de principios, relacionan los problemas de índole estrictamente a los órdenes normativos superiores del ordenamiento jurídico, dado que son normas que responden a una jerarquía constitucional y ya vienen todas de validez jurídica. "El concepto colisión de principios presupone la validez de los principios en colisión. Por ello, la referencia a la posibilidad de catalogar a los principios como inválidos no afecta el teorema de la colisión, sino que revela uno de sus presupuestos". (Alexy, 2007, p. 86).

El segundo aspecto que tratan los principios y su carácter absoluto, busca demostrar que si los principios responden a una idea de principios absolutos estos no tendrían precedencia en las colisiones, y a su vez no sería necesario la ponderación. Ya que precisamente no existiría colisión alguna, teniendo que el concepto de precedencia condicionada, del cual dedicamos unos renglones atrás, explica que los principios en sí presentan validez dentro del sistema jurídico, en el caso particular y concreto, en el que uno dejaría de aplicarse para que el otro no se llegue a concretar. Si los principios fueran absolutos no tendrían que aplicarse por precedencia en condiciones particulares, ya que existirían solo principios que precederían a todos los demás principios que pertenecen al sistema jurídico, y su aplicación en concreto no fuese necesaria. Esto se debe también a que el uso de la ponderación de normas fundamentales de principios se refiere a bienes colectivos y a bienes particulares, lo cual la incidencia o no de los principios va a estar determinada por el suficiente grado de afectación de los principios contrapuestos sobre los titulares de tales derechos. 
Finalmente, sobre la tercera objeción, en el concepto amplio de principio, que indica que si el concepto de principio es lo suficientemente amplio, abarcaría todos los intereses que resolverían las ponderaciones o juicios constitucionales ${ }^{23}$, y se estaría en la imposibilidad de que concretamente se relativicen los intereses en colisión. Sobre este punto en particular se destaca, que el concepto amplio de principio debe entenderse en el sentido de que los principios se vean como intereses colisionados sin límites a fines materiales, que los intereses a los que respondan cada principio no sean ilimitados o infinitos.

La relación de principios en colisión debe responder a intereses dados por los propios derechos fundamentales que entran en colisión. Más bien, "el concepto amplio de principio debe pensarse, como una idea de límite y de diferenciación en los intereses, sean estos de derecho a fines, a intereses colectivos o de derecho a fines, a intereses individuales". (Alexy 2007, p. 87). Sobre el particular menciona que DWORKIN al referirse al concepto de principio en sentido amplio o genérico, solo destaca que los principios son solo aquellas normas que es posible aducir como razones para derechos individuales, ya que DWORKIN habla que las normas que se refieren a bienes colectivos, deben ser entendidas como políticas y no como principios ${ }^{24}$ en su sentido general y amplio.

En este orden de ideas, como ya lo habíamos reiterado, a diferencia de las reglas, los principios no entran en un juicio de valor, que determine cual norma de principio no tiene validez. Aquí lo que se entra a determinar en la dimensión del peso, es cual, de los dos principios, atendiendo a las circunstancias del caso concreto se ponderaría a los respectivos intereses. El modelo puro de los principios permite que las relaciones de los intereses en colisión construyan las ponderaciones concretas de disolución, a objeto de bienes colectivos o individuales. Esto se presenta, porque los dos principios opuestos y en contradicción ya pertenecen al sistema jurídico, por orden concreto de la Constitución nacional, o en el caso que examinamos por la ley fundamental (alemana) lo que distingue totalmente el modelo puro de reglas, al modelo puro de principios ${ }^{25}$.

\footnotetext{
${ }^{23}$ Sobre el juicio constitucional aplicado en Colombia, frente a las cargas del juez para tomar la decisión de derechos fundamentales observar: Bechara, A. (2017b). La carga invertida de los derechos fundamentales como procedimiento de creación judicial: diálogo jurisdiccional en la garantía de protección secundaria. La Creación judicial del derecho y el diálogo entre jueces. Universidad Autónoma de Barcelona.

24 "Dworkin contrapone a este modelo de reglas del sistema jurídico un modelo de principios. Según el modelo de principios, el sistema jurídico está compuesto, además de reglas, de un modo esencial, por principios jurídicos. Los principios jurídicos deben permitir que también exista una única respuesta correcta en los casos en las que las reglas no determinan una única respuesta". (Alexy, 1988, p. 139).

${ }^{25}$ La aplicación de los principios en los planos concretos propone, un proceso de discusión racional, cuando existe más de una posibilidad para tomar la decisión en particular, este precisamente es el papel de los argumentos de principio, sopesar las razones a favor o en contra de determinado bien jurídico. Sobre este punto en particular, encontramos apoyo, siguiendo a Juan Ruiz Manero desde su concepción de principios: "Los principios no pueden ser vistos más que como razones de primer orden (como razones para hacer lo ordenado cuyo peso frente a otras razones en contra de ello no puede establecerse más que mediante deliberación) precisamente porque no determinan en qué condiciones debe hacerse (concluyentemente) lo ordenado". (Ruiz Manero, 2005, p. 344). En: Ruiz Manero, J. (2005). Principios, objetivos y derechos. Otra vuelta de tuerca. En: Revista Doxa, Cuadernos de filosofía del derecho. №. 28. pp. 341-365.
}

Justicia Vol. 24 No. 36: pp. 196-213. julio - diciembre, 2019. DOI: 10.17081/just.24.36.3765 
Si bien, tanto las reglas como los principios ${ }^{26}$, y en este referente encontramos una similitud o semejanza, está en que ambos, principios ${ }^{27}$ y reglas son normas jurídicas, que protegen bienes $o$ intereses individuales y colectivos, pero se diferencian sustancialmente, precisamente en su estructura, en lo que indica la forma en que serán resueltos sus conflictos (reglas) y las colisiones (principios) de ambas normas en general.

Nosotros somos de la posición, que el modelo puro ${ }^{28}$ de principios no es del todo ineficaz para construir un modelo ponderativo en la solución de colisiones de principios, lo que ocurre es que el modelo debe nutrirse de fundamentos construidos a partir de un modelo de principios objetivo, en la determinación de sus propios intereses. Y este se logra si, se miran a los principios como normas jurídicas de mandatos a circunstancias concretas, es decir, son normas que expresan un alto grado de generalidad por su concreción particular, pero esta permite optimizar el derecho fundamental que responda al mayor grado de intereses que deben ser protegidos.

\section{SIECKMANN Y LOS PRINCIPIOS COMO ARGUMENTOS NORMATIVOS DE RAZONES}

Esta propuesta de observar a los principios como argumentos normativos de razones ${ }^{29}$, para la construcción de un método ponderativo con especial distinción como modelo argumentativo de derechos fundamentales, en cuya característica intrínseca reposan las normas de principio, en un ámbito de consolidación racional se apoya fundamentalmente a una crítica, propuesta por SIECKMANN al modelo ponderativo de ALEXY, sobre los principios vistos como mandatos de optimización, de realización conforme a las posibilidades fácticas y jurídicas del caso concreto tal como lo indica:

${ }^{26}$ Desde la perspectiva de los principios de Alexy, desarrollada en el Estado constitucional colombiano, y en la jurisprudencia de los derechos fundamentales en Colombia, observar: Bechara, A. (2019). Jurisprudencia de principios e interpretación de los derechos fundamentales. Editorial Universidad del Norte. Barranquilla, Colombia. Carrillo, Y. \& Bechara, A. (2019). La balanza de los derechos. Editorial Ibáñez. Bogotá, Colombia. Molinares, V; \& Bechara. (2017). Entre la interpretación y la norma: la tasa razonable de justificación constitucional. Revista de Derecho. No 48, pp. 163-188.

${ }^{27}$ El modelo puro de principios, presenta también una objeción o critica importante. Es aquella que se refiere a que la construcción de un modelo ponderativo, como restricción a los derechos fundamentales, desconocería la constitución positiva o escrita, e implicaría una desmedida a los límites racionales de los derechos fundamentales como normas de principios. Además, atentaría con el sentido institucional de la misma constitución y cambiaria esta, de rígida a flexible.

${ }^{28}$ Sobre esta afectación al modelo puro de principios Alexy (2007) indica: "No hay duda de que esta objeción afecta un punto importante del modelo puro de los principios. Puede, desde luego, discutirse que es lo que significa la vinculación a la constitución y si, en determinados casos, está permitido apartarse del texto constitucional. Pero, en cambio, es indiscutible que, por lo general, hay que partir del texto de la constitución y que, en caso de que este permitido apartarse del texto constitucional, ello solo puede ocurrir por razones especiales". (p.97).

${ }^{29}$ Sobre el caso puntual, de los principios como argumentos normativos de razones Sieckmann (2014) destaca la diferencia, entre los principios vistos como objetos de la ponderación, y los principios vistos como juicios ponderativos, que especialmente, sobre este punto de la teoría Alexyana, nosotros nos adherimos a la crítica de Sieckmann a Alexy: "la concepción de los principios como argumentos normativos asume que los principios no solo son los objetos de las ponderaciones , sino que constituyen razones para los juicios ponderativos, según esta idea, los principios son normas que se utilizan como argumentos a favor de juicios de la ponderación". (pp. 187-188). En: Sieckmann, J. (2014). La teoría del derecho de Robert Alexy. análisis y crítica. Universidad Externado de Colombia, Serie de Teoría jurídica y filosofía del derecho. №. 67. Bogotá, Colombia.

Justicia Vol. 24 No. 36: pp. 196-213. julio - diciembre, 2019. DOI: 10.17081/just.24.36.3765 
La definición Alexyana de los principios como mandatos de optimización y como mandatos que deben optimizarse se ve enfrentada a severas objeciones, y como alternativa se propone una concepción de los principios como argumentos normativos que constituyen razones para los juicios de ponderación. (Sieckmann, 2011, p.19).

Si bien este aspecto, es una construcción propia de SIECKMANN, nosotros proponemos como complemento para la construcción del modelo de ALEXY, que la ponderación como método para solucionar colisiones que expresan en su contenido material derechos fundamentales ${ }^{30}$, en evidencia contraposición, debe ser vista desde su dimensión cualitativa, mas no desde una dimensión cuantitativa que el propio ALEXY le ha querido dar a su ponderación propuesta en la Teoría de los derechos fundamentales, debido a que ALEXY al utilizar herramientas propias de la lógicamatemática, y más concretamente cuando se refiere a la fórmula del peso al querer darle un peso en abstracto a cada principio que se pondera, y así solucionar las colisiones o las posibles contraposiciones de principios.

Bajo dicho sentido, nos apartamos del modelo Alexyano, pues concebimos que la ponderación deba ser orientada a una valoración cualitativa de las razones de peso que fundamentan a favor o en contra de determinado principio sobre otro y su posterior precedencia para su aplicación en concreto. Consideramos que en este aspecto se evidencia el verdadero valor de las ponderaciones o ponderación ${ }^{31}$ de principios, en determinar de manera valorativa como un argumento razonable juega a favor o en contra en la determinación de cada principio o derecho fundamental en colisión ${ }^{32}$.

A la hora de entrar a ponderar principios en colisión, estos pueden verse como su objetivo central, en tratar de identificar la optimización del mandato que busca la realización de un principio en el caso concreto. Fundamentalmente uno de los criterios utilizados en esta construcción, es la distinción entre reglas y principios, como la distinción para entender una teoría de los principios y a ellos mismos como mandatos de optimización. Si tenemos en cuenta que si bien las reglas en cuanto a normas jurídicas estructuralmente distintas a los principios, atenderán sus soluciones apelando al modelo puro del silogismo jurídico, que presenta el modelo de la subsunción, enfrentando el método en la formula todo o nada imposibilitando una lectura, de las normas de textura

30 Sobre la dimensión material de los derechos fundamentales, aplicada al sistema jurídico colombiano ver: Bechara, A. (2016). Nuevos sujetos de especial protección constitucional: defensa desde la teoría principialista de los derechos fundamentales. Justicia. Vol. 21, no 29. Bechara, A. (2017a). Jurisprudencia de principios e interpretación de la Constitución: El escenario de la Corte Constitucional colombiana. Justicia. Vol. 32, p. 15-37.

${ }^{31}$ Una visión positivista de la ponderación, es defendida por: Aguiló, R. (2000). Teoría general de las fuentes del derecho. Primera edición. Editorial Ariel. Barcelona, España. (...) “la llamada ponderación de principios no es otra cosa que la selección de la solución normativa que debe resolver el conflictivo cuando sobre el mismo concurren varios principios. Se selecciona la solución normativa establecida por el principio que a luz de las propiedades del caso tiene más peso. En este sentido, pues, los principios son menos importantes que las reglas: incorporan soluciones normativas (deber de tratar igual, deber de no dictar retroactivas, etc.) pero no indican cuando (en qué casos) rigen esas soluciones". (p. 138).

32“Los principios son argumentos normativos que tienen la estructura de mandatos reiterados de validez, mientras que las reglas son el significado de enunciados normativos que expresan los resultados de una argumentación. Por consiguiente, los argumentos normativos exigen que cierta norma o enunciado normativo sea aceptado, y sea validado como resultado de sopesar o ponderar los argumentos que entran en colisión". (Sieckmann, 2006, p. 82). 
abierta propia de los derechos fundamentales, aquí no habría optimización o ponderación alguna.

Es así, que la dificultad de tal distinción (reglas y principios) puede presentarse en lo que ALEXY establece como ley de ponderación, según la cual cuanto mayor es el grado de la no satisfacción o afectación de un principio, tanto mayor tiene que ser la importancia de la satisfacción del otro principio, sobre esto nos preguntamos. ¿Qué ocurriría según la ley de la ponderación sino se pudiera establecer el grado de la mayor o máxima satisfacción del otro principio? ¿Con relación al principio contrapuesto se pensaría que no habría una ponderación pues la fórmula de optimización del mandato no podría aplicarse por cuando todo sería el resultado de la no aplicación de alguno de los principios en colisión? Lo que nos pondría a pensar y a representarnos los principios como argumentos normativos o argumentos de principio ${ }^{33}$ a favor o en contra de las razones de derechos fundamentales.

En el sentido de los principios como razones para una argumentación ponderativa, estos deben ser vistos desde el punto de vista normativo no solo como mandatos de optimización como lo mencionábamos en el párrafo anterior, ni inclusive como normas prima facie, que indican que algo sea posible de realizar en la primera medida de circunstancias fácticas, ya que en esta intensión de la medida, es importante considerar los principios contrapuestos en colisión conjuntamente, como dos normas que quieren encontrar un espacio en la situación puntual que se pondera. Un caso concreto de un argumento que se construye con la idea de optimización lo presenta SIECKMANN (2011) en su visión de los derechos fundamentales como principios:

Una norma prima facie puede formularse, por ejemplo, de este modo: en casos normales, también las manifestaciones de opinión que lesionan el honor están permitidas. O también así: según los argumentos disponibles hasta ahora, también las manifestaciones de opinión que lesionan el honor están permitidas. Ninguna de ambas normas, sirve de argumento para una decisión ponderativa, porque el enunciado sobre lo que es válido en casos normales, o según el estado actual de la argumentación, no entrañan ninguna proposición acerca de cómo haya de resolverse o decidirse de una colisión con principios contrapuestos. Lo mismo vale para la interpretación de una norma como: las manifestaciones de opinión están permitidas. (p.32).

\section{CONCLUSIONES}

La separación que hace DWORKIN de las normas (reglas) jurídicas y de los normas (principios) jurídicos permite determinar el método de aplicación de las reglas y su diferencia de la forma de aplicar los principios, posibilitando para la actividad judicial en los casos en los que el operador jurídico no encuentre la norma valida aplicable una metodología para construir su decisión en contra de un uso desmedido de la discrecionalidad. Nos apartamos parcialmente del modelo Alexyano, pues concebimos que la interpretación y justificación de los derechos fundamentales, deba ser orientada a una valoración cualitativa de las razones de peso que fundamentan a favor o en contra

\footnotetext{
33 "Los argumentos de principio son de particular significación. En los Estados constitucionales democráticos, los argumentos de principio se apoyan esencialmente en los preceptos constitucionales. $\mathrm{Su}$ utilización incluye en casos difíciles normalmente una ponderación, lo cual indica que los principios tienen el carácter de preceptos de optimización”. (Alexy, 1995, pp. 57-58).
}

Justicia Vol. 24 No. 36: pp. 196-213. julio - diciembre, 2019. DOI: 10.17081/just.24.36.3765 
de determinado principio sobre otro y su posterior precedencia para su aplicación en concreto.

Finalmente, las razones ponderativas de los argumentos de principio en SIECKMANN van a determinar si en los casos concretos o no, la precedencia de un principio sobre otro en colisión, son razones fundamentadas que se apoyan en elementos valorativos de la argumentación jurídica y de su discurso práctico general, no dejándose llevar a aspectos volitivos o del querer de quien realiza en el procedimiento ponderativo. Lo que resulta sumamente interesante, ya que se puede llegar a pensar por la doctrina mayoritaria en Colombia, que la Teoría de los derechos de ALEXY, y su visión de la construcción aplicada de las normas y disposiciones de principios, es la vista hegemónica en el contexto de formación alemán de los derechos fundamentales, y lo que evidencia la teoría de los principios y los derechos de SIECKMANN, es que pueden coexistir teorías complementarias en una fase triádica conceptual, esto es (i). La filosofía del derecho, (ii). La teoría constitucional y de los derechos fundamentales, y (iii). La teoría de la interpretación y argumentación de la Constitución y la ley.

\section{REFERENCIAS}

Aguilera, R. (2009). La función de la filosofía política y jurídica en Ronald Dworkin. En: Revista Multidisciplinar del Centro de estudios sobre derecho, globalización y seguridad. Universidad Veracruzana. Núm. 20. Año 10. pp. 1-16.

Aguiló, R. (2000).Teoría general de las fuentes del derecho. Primera edición. Editorial Ariel. Barcelona, España.

Alexy, R. (1993). Derecho y razón práctica. Distribuciones Fontamara. México, D.F.

Alexy, R. (1995). Teoria del discurso y derechos humanos. Traducción de Luis Villar Borda, Universidad Externado de Colombia. Serie de teoría jurídica y filosofía del derecho. $\mathrm{N}^{\circ}$. 1. Bogotá, Colombia.

Alexy, R. (2007). Teoría de los derechos fundamentales. ( $2^{\circ}$ ed.). Centro de estudios políticos y constitucionales. Madrid, España.

Alexy, R. (2009). Derechos fundamentales, ponderación y racionalidad. En: Revista Iberoamericana de Derecho Procesal Constitucional. núm. 11, enero-junio, pp. 3-14.

Amandi, V. (2007). Ronald Dworkin y los principios generales del derecho. Editorial Porrúa. DF. México.

Bechara, A. Estado constitucional de derecho, principios y derechos fundamentales en Robert Alexy. En: Revista Saber Ciencia y Libertad. V. 6, №. 2. pp. 63-76.

Bechara, A. (2016). Nuevos sujetos de especial protección constitucional: defensa desde la teoría principialista de los derechos fundamentales. Justicia. Vol. 21, no 29.

Justicia Vol. 24 No. 36: pp. 196-213. julio - diciembre, 2019. DOI: 10.17081/just.24.36.3765 
Bechara, A. (2017a). Jurisprudencia de principios e interpretación de la Constitución: El escenario de la Corte Constitucional colombiana. Justicia. Vol. 32, p. 15-37.

Bechara, A. (2017b). La carga invertida de los derechos fundamentales como procedimiento de creación judicial: diálogo jurisdiccional en la garantía de protección secundaria. La Creación judicial del derecho y el diálogo entre jueces. Universidad Autónoma de Barcelona.

Bechara, A. (2019). Jurisprudencia de principios e interpretación de los derechos fundamentales. Editorial Universidad del Norte. Barranquilla, Colombia.

Carrillo, Y. \& Bechara, A. (2019). La balanza de los derechos. Editorial Ibáñez. Bogotá, Colombia.

Dworkin, R. (1984). Los derechos en serio. Primera edición, Traducción de: Marta Guastavino. Editorial Ariel. Barcelona, España.

Dworkin, R. (2012). El imperio de la justicia. Segunda edición, Traducción de: Claudia Ferrari. Editorial Gedisa. Barcelona, España.

Habermas, J. (2008). Facticidad y validez. Quinta edición, Trad. de Manuel Jiménez Redondo. Editorial Trotta. Madrid, España.

Molinares, V; \& Bechara. (2017). Entre la interpretación y la norma: la tasa razonable de justificación constitucional. Revista de Derecho. No 48, pp. 163-188.

Ruiz Manero, J. (2005). Principios, objetivos y derechos. Otra vuelta de tuerca. En: Revista Doxa, Cuadernos de filosofía del derecho. №. 28. pp. 341-365.

Sieckmann, J. (2006). El modelo de los principios del derecho. Universidad Externado de Colombia. Serie de teoría jurídica y filosofía del derecho. № . 43. Bogotá, Colombia.

Sieckmann, J. (2014). La teoría del derecho de Robert Alexy. Análisis y crítica. Universidad Externado de Colombia, Serie de Teoría jurídica y filosofía del derecho. №. 67. Bogotá, Colombia.

Sieckmann, J. (2011) Los derechos fundamentales como principios. En: Sieckmann, J. (ed.). La teoría principialista de los derechos fundamentales. Editorial Marcial Pons. Madrid. España. 